\title{
Brainspotting Therapy: About a Bataclan Victim
}

\author{
Joanic Masson ${ }^{1}$, Amal Bernoussi ${ }^{1} \&$ Charlemagne Simplice Moukouta ${ }^{1}$ \\ ${ }^{1}$ Center of psychology (EA 7273), University of Picardy Jules Verne, 80025 Amiens, France \\ Correspondence: Dr Joanic Masson, Center of Psychology, UFR Sciences Humaines et Sociales, Chemin du Thil, \\ 80025 Amiens Cedex, France.
}

Received: February 7, 2017 Accepted: March 16, 2017 Online Published: May 29, 2017

doi:10.5539/gjhs.v9n7p103 URL: https://doi.org/10.5539/gjhs.v9n7p103

\begin{abstract}
Brainspotting psychotherapy (BSP), elaborated by Grand in 2003, aims at managing patients suffering from psycho-traumatic syndromes: Post-Traumatic Stress Disorder, emotional dysregulation, anxiety and/or depressive syndromes.

This original approach combines features of hypnotherapy and EMDR (Eye Movement Desensitization and Reprocessing) and is based on the concept of eye positions capable of soliciting the psychological assimilation processes of traumatic memories. We briefly present this therapeutic tool (framework, protocol, expected effects) and propose certain hypotheses which may explain its efficacy. For this, we draw on research into the practice of Mindfulness and the theory of mnesic malleability. Finally, the follow-up of a victim of the 2015 attack on the Bataclan in Paris supports the discussions developed here.
\end{abstract}

Keywords: brainspotting therapy, psycho-traumatic syndromes, mindfulness, memory re-consolidation

\section{Introduction.}

Brainspotting therapy (BSP) is a psychotherapeutic approach elaborated by Grand (2013) from EMDR (Eye Movement Desensitization and Reprocessing, Shapiro, 1989) and Somatic Experiencing. (SE, Levine, 2010) This psychotherapeutic tool aims essentially at managing psychological traumas and their associated effects: Post-Traumatic Stress Disorder, emotional dysregulation, anxiety and depressive disorders, etc. (Masson, Bernoussi, Cozette Mience, \& Thomas, 2013; Masson, Bernoussi, Gounden, Moukouta, \& Njiengwe, 2016) Grand hypothesizes that the visual field may be used to activate the "Adaptive Information Processing" system (Shapiro, 2001), i.e. a process of assimilating dysfunctional information, or traumatic memory. This consists of localizing strategic eye positions in the patient's visual field, known as "Brainspots", considered to correlate to neurological activation and the dysphoric experience. The "Brainspot" is as it were a neurophysiological response to the targeted activation (emotional dysregulation) associated with a specific eye position. According to Grand, it consists of sub-cortical cerebral activity in response to sustained attention at a specific eye position.

\section{Presentation of Brainspotting.}

In order to determine these "Brainspots", the practitioner guides the patient towards an emotional and somatic activation linked to the problem to be treated, in particular a traumatic memory. The subject is encouraged to focus attention on the inner experience, so as to elicit the suffering to a maximal degree. It is recommended, as in EMDR, to evaluate its intensity using a subjective scale (SUD, Subjective Unit of Disturbance) from 0 to 10 and to localize the most intense corporal activation. Moreover, naming the localization tends to deepen the emotional feeling.

The practitioner carries out a slow back-and-forth sweeping movement with his fingers (or with a stick) horizontally across the visual field of the patient, who is guided to follow the movement with the eyes and keep the face still, while focusing attention on the activation felt. At a specific point, or "Brainspot", an eye reflex may be observed (eye-jerk, freezing, blinking, etc.) and/or a body movement (facial tic, frown, sniff, swallow, nod, shifting of part of the body, rapid breathing, etc.), indicating increased activation. It is also possible to use patient feedback to localize the point more precisely within the visual field.

Then, as in EMDR, the patient is asked to focus continually on the object (fingers, or the tip of the stick) while concentrating on what $\mathrm{s} / \mathrm{he}$ is feeling: thoughts, emotions, sensations. Particular attention is drawn to corporal sensations, which tend to amplify the introspective process. The associated processes are followed - ideally - until a 'SUD $=0$ ' is reached when the subject focuses attention on the original target memory. According to Grand, the 
specific feature of BSP - also found in EMDR and other psychotherapies - is guiding the patient's attention towards what $\mathrm{s} / \mathrm{he}$ is feeling. He suggests calling this attitude one of "focused mindfulness". Analogous to the practice of meditation, the subject continually focuses attention, thus preventing any avoidance attitudes. It consists of a confrontation of oneself, a confrontation of what is most often avoided: the suffering and its origin. The author of Brainspotting therapy has progressively elaborated different variants, detailed in his book. (Grand, 2013) These diverse procedures aim at broadening the search for Brainspots to the whole visual field, rather than to just its horizontal element ("Inside Window BSP", "Outside window BSP", "Gaze-spotting", "Z-Axis BSP"), or using a comfort zone as the departure point ("Resource BSP") for accentuating psychological resources. It's also possible to work with only one eye ("One Eye BSP"), considering that there is one eye conducive to comfort and the other to traumatic activation.

Brainspotting psychotherapy draws on a Dual Attunement Frame:

- A "relational tuning" referring to the therapeutic tuning: the secure, inclusive attachment to the therapist, which is the base of psychotherapy in general, soliciting social engagement;

- A "neuro-biological tuning" which requires attention to the neuro-physiological aspects solicited via somatic behavior in order to provide better guidance of the therapeutic process.

We have observed, compared to our long experience of EMDR (nearly 10,000 sessions undertaken), that BSP induces an in-depth treatment of the traumatic memory more rapidly and that this is experienced generally less painfully than with EMDR: rapid access to a somatic encoding of the dysfunctional information, an effect most often felt right from the very first session. This is a clinical observation, derived from consultants' remarks and observations, which would benefit from being studied more rigorously.

\section{Clinical Case}

Below we present the rapid management of Pierre, aged 30, suffering from a post-traumatic stress disorder. The patient has given his written permission for this session and his notes to be used for the purpose of this publication. Pierre was present during the terrorist attack at the Bataclan in Paris on November $13^{\text {th }}, 2015$. Having gone with friends to see the concert by the American band Eagles of Death Metal, the patient remained nearly an hour and twenty minutes lying motionless in the stage pit, while heavily-armed gunmen were carrying out the massacre. Rescued by the police and army, Pierre and his friends sustained some injuries in the attack. Seven months later we met the patient, who had rapidly been taken into psychiatric care. He had been seen in consultation by a psychiatrist on a more or less weekly basis. This initial psychological support consisted essentially of psychotherapy consultations following the psychopathology assessment, which revealed a post-traumatic stress disorder. We had arranged to meet for a session of around two hours to carry out a psychopathology assessment and an initial session of BSP. Pierre also wished to express what he had experienced during the attack, as well as his suffering and the BSP therapy:

"On November 13" 2015 , I was in the Bataclan concert hall, towards the front right of the stage pit, when the gunmen entered around 9:40pm. I got out 1 hour and 40 minutes later, around 11:20pm. During this time and without being exhaustive, what I experienced can be summarized in 7 points:

- I was hit by a bullet on the chin as I turned towards the gunmen when they opened fire.

- I experienced about 12 minutes of intense firing.

- After that I remained for around an hour and twenty minutes lying on the floor in the stage pit, unable to see: just hearing. I was on top of a group of about ten people at most, lying one or two deep. I was thus permanently and potentially exposed to the gunfire.

- During this time, one of the gunmen activated his explosive belt a few meters away from us, then the other gunmen continued firing one or two rounds a minute into the stage pit from the upper balconies.

- I discovered what it was to lose all hope of getting out of the stage pit alive and of surviving.

- When the agents of the Search and Intervention Brigade (BRI) and the Search, Assistance, Intervention and Deterrence squad (RAID) entered the stage pit without speaking, we first thought that it was the gunmen, coming to load us with explosives.

- When I picked myself up, I looked for my friends in the stage pit, without finding them: what I saw became rapidly unbearable."

The assessment revealed a characteristic psycho-traumatic syndrome: flashbacks, pain, dysregulation of the autonomous nervous system, increased anxiety and depressive affects, as well as avoidance behavior. 
"Six months after the Bataclan, I was still having lots of nightmares: two or three a week. The memories which were coming back to me on a daily basis were causing me severe pain, particularly in my chest. These memories were always the same: the images, the moments or even the screaming at the first sound of gunfire. In addition Ifelt a certain sadness every day, especially when I was alone. It was these things which motivated me to undertake some work on a technique like BSP."

We then proceeded with the psychotherapy treatment:

"On the first session, I started by focusing on a difficult memory while concentrating on the pain that it caused me. By keeping my hand on my chest, I felt a burning sensation getting stronger and stronger, and also my heart beating harder and harder. This pain reached a climax, then ... it died down, giving way to a feeling of peace and well-being. This well-being materialized in my thoughts as a vision of a beautiful peaceful meadow by the sea. My mind then switched straight away to another memory: the effects were identical. I sometimes felt myself shedding tears, but for each memory, the pain climaxed then diminished, giving way to a feeling of well-being and the urge to smile... I came out of the session exhausted... The effects were visible from the very next morning. It was the first morning (as every morning since then) that I didn't think about the Bataclan as soon as I woke up. I woke up smiling, with pleasant music in my head. At breakfast, my girlfriend told me I was looking well ... for the first time since the Bataclan.

Weeks later, I can recap the effects of this work in six points:

- I can think back on these memories without the pain coming back.

- $\quad$ The daily feelings of sadness have totally disappeared.

- I am in much better physical shape.

- I once again feel like chatting with people - at work, at the store, with friends - and it makes me feel good.

- I Ifeel much more connected to my physical and relational environment, much more concentrated on the present moment too.

- $\quad$ My posture in public spaces has changed: I no longer walk in the street with that sense of insecurity.

To conclude, I would say that this technique doesn't resolve everything, but it resolves the main things. And that is already quite enough to feel a real 'before and after' effect. This work has considerably changed my daily life, and in a very positive way."

The BSP session enabled assimilation of the traumatic memory. This can be observed through precise criteria: disappearance of flashbacks, extinction of pain, anxiety and depressive affects, disappearance of avoidance behavior and the feeling of insecurity. Furthermore, these modifications are reflected through Pierre's gesture, his relationship with the environment, the disappearance of fatigue, and the absence of any suffering when he thinks back over what he has gone through. We note that these effects are still present nearly three months after our single session of treatment, as the patient relates:

"Three months after our sessions, the pains have not come back. The memories come back on a daily basis, more or less significantly, depending on the day, but I no longer feel the pains associated with those memories especially in my chest. That's something really positive.

I don't have anything like as many nightmares: I would say about one nightmare every two or three weeks, even four. Before our sessions, the nightmares were about gunfire and shooting. These days, the few nightmares that I've had over the last three months present a feeling of being "trapped": it's impossible to get out of a situation which will cause my death. I sometimes cry the day after these nightmares. As I have explained to my girlfriend, they bring back the feeling I had when I was lying in the stage pit, unable to get out."

Several sporadic nightmares persist, demonstrating that a second session might enable a further assimilation of the remaining dysfunctional information. It's possible that over time this process will operate spontaneously and naturally. We note that the patient did not wish to participate in a second session: possibly considering that the obtained result was sufficient.

\section{Discussion.}

The clinical practice of Brainspotting demonstrates a flux of psychological and emotional as well as physical processes. The patient describes an alteration in consciousness associated with the absorption derived from the hypnotic focalization induced by visual fixation. The associations of ideas are fertile, as are the emotional and 
somatic feelings. The abreactions experienced are often less intense than in EMDR and hence the sessions are better tolerated. Few rigorous studies have been carried out to date but clinical experience demonstrates a near constant resolution of traumatic experiences: detachment from memories, disappearance of painful emotions $(\mathrm{SUD}=0)$, a profound physical relaxation even when focusing attention on the initially painful memory. Furthermore, we observe a sustainable and progressive attenuation of the symptoms which brought the patient to consultation.

This assimilation occurs through a process of letting-go, favored by the proposed framework: alteration of the state of consciousness; abandon to the experience without feeling under control; constant attention to emerging feelings. In effect, focused mindfulness constitutes a lever mechanism essential to this approach, while localization of the "Brainspot" with constant concentration on it favors a hypnotic state and "letting-go". (Masson, Bernoussi, \& Regourd-Laiseau, 2016)

This is not unlike what is proposed in Acceptance and Commitment Therapy (ACT, Hayes, Strosahl, \& Wilson, 1999), which considers psychological suffering associated with weak detachment as internal experiences lived out as the reflection of reality. The patient remains focused on a painful past or/and an anxiety-provoking future and continuously seeks to avoid the suffering, which in turn helps to maintain it. Furthermore, ACT aims at developing acceptation of the emotional experience, a disconnection from it, an enhanced contact with the present moment and, hence, a change in perspective.

Just as with ACT, BSP enables development of psycho-somatic-emotional flexibility, conducive to a beneficial internal reorganization. This flexibility is enabled through attentive presence, so characteristic of ACT and BSP. Traditionally, attentive presence is a Buddhist spiritual practice (meditation) allowing one to realize the nature of consciousness - for its part impermanent and ephemeral - as well as the origin of suffering.

Gregoire, Lachance \& Richer (2016) qualify Mindfulness as a secular practice, i.e. without spiritual and religious reference, capable of regulating attention, favoring enhanced treatment of information, modulating reactions to emotions, reinforcing executive control and consequently favoring improved mentalization.

Memory re-consolidation theory proposes a complementary hypothesis capable of explaining the efficacy of BSP. This theory considers that a memory becomes sensitive to degradation when it is re-memorized. The activity of remembering renders the memory labile as it were and can thus favor a different biological re-encoding of this same information. Furthermore, memory is a constant process of reconstruction which re-actualizes what has been encoded according to the emotional experience of the present moment. (Levine, 2015)

The emotional state at the time of re-actualization of the memory will transform the memory in question. Hence, working in attentive presence within a therapeutic framework and a reassuring relationship with the therapist brings the patient to re-actualize the traumatic memory within a comforting space. This facilitates an accentuation of emotional tolerance, enhanced auto-regulation and the possibility of transforming not only the experience, but also the beliefs and perspectives attached to the memory.

A clinical observation, also reported by Grand (2013), requires mention due to its substantial interest. With numerous patients, we have proceeded to BSP sessions on target memories already treated by EMDR. These could be considered to have been resolved in terms of EMDR criteria: $\mathrm{SUD}=0$, Validity of cognition $=7$, body scan $=$ complete relaxation. Nonetheless, new psychological matter emerged in BSP that the subjects weren't aware of. It seems that the initiated treatment is localized at a deeper level than in EMDR. What's more, the subjects describe an impression of having delved even deeper into themselves. Of course, it is possible that this same type of observation might have been manifested by further EMDR sessions. Nevertheless, the descriptions given by the subjects having experienced one or more sessions of BSP conjure up, over and over again, this impression of a long voyage into the inner depths of themselves, where they were able to grasp a trouble, a suffering, which had been there for a long time, and of which they had not been able to rid themselves.

This particularity is possibly linked to an observation made by Grand: that's to say a 'SUD $=0$ ' does not designate complete assimilation of the dysfunctional network. The author has thus developed a procedure, called "squeezing the lemon", which in some way enables the adaptive mechanisms of resistance to be 'overcome'. The patient is asked to focus on him/herself and to do everything possible to re-activate the suffering, ready to be re-treated by BSP. This procedure is repeated until no further activation can be generated. "Squeezing the lemon" appears to be a strategy to counter the subject's defenses and to force an even deeper treatment of anything that hasn't been assimilated.

\section{Conclusion.}

Brainspotting psychotherapy constitutes a clinically fertile holistic approach which nevertheless requires further 
rigorous study in order to validate its efficacy and determine the operating factors. To that effect, our team is currently initiating research to assess this therapeutic tool with victims of sexual abuse. As a first step, we have sought to demonstrate in this article a factor that might explain its effectiveness: focused mindfulness, which would favor a re-treatment of the mnesic memory. Furthermore, the BSP clinic leads us to believe that traumatic matter is encoded at different levels within the individual. Indeed, we think that various spheres are solicited: psychological (thoughts, beliefs, memories, representations); emotional (fear, anxiety, sadness, anger, shame, guilt, etc.); and somatic (dysregulation of the autonomous nervous system in particular, somatic defense reactions)

It is also legitimate to consider various levels within each of these spheres that psychotherapy should be able to affect, in order to claim complete resolution of the traumatic experience. (Ogden, Minton, \& Pain, 2015)

Brainspotting therapy seems to enable this and thus appears to be a naturalistic approach, capable of reactivating the subject's resilient resources.

\section{Competing Interests Statement}

The authors declare that they have no competing or potential conflicts of interest regarding the publication of this paper.

\section{References}

Grand, D. (2013). Brainspotting: The revolutionary new therapy for rapid and effective change. Boulder: Sounds True.

Gregoire, S., Lachance, L., \& Richer, L. (2016). La présence attentive (mindfulness). Québec: Presses de l'université du Québec.

Hayes, S.C., Strosahl, K. \& Wilson, K.G. (1999). Acceptance and Commitment Therapy: An experiential approach to behavior change. New York: Guilford Press.

Levine, P. A. (2015). Trauma and memory. Brain and body in a search for the living past. A practical guide for understanding and working with traumatic memory. New York: North Atlantic Books.

Levine, P. A. (2010). In an unspoken voice: How the body releases trauma and restores goodness. New York: North Atlantic Books.

Masson, J., Bernoussi, A., \& Regourd-Laiseau, M. (2016). From the influences of trauma to therapeutic letting-go: the contribution of hypnosis and EMDR. International Journal of Clinical and Experimental Hypnosis, 64(3), 350-364. https://doi.org/10.1080/00207144.2016.1171108

Masson, J., Bernoussi, A., Cozette Mience, M., \& Thomas, F. (2013). Complex Trauma and Borderline Personality Disorder. Open Journal of Psychiatry, 3, 403-407. https://doi.org/10.4236/ojpsych.2013.34044

Masson, J., Bernoussi, A., Gounden, Y., Moukouta, C. S., \& Njiengwe, F. E. (2016). Psycho-traumatic evaluation of identity (PEI): Example of depressive disorder. Open Journal of Psychiatry, 6, 262-272. https://doi.org/10.4236/ojpsych.2016.64031

Ogden, P., Minton, K., \& Pain, C. (2015). Le corps et le trauma. Bruxelles: De Boeck.

Shapiro, F. (1989). Efficacy of the eye movement desensitization procedure in the treatment of traumatic memories. Journal of Traumatic Stress, 2, 199-223. https://doi.org/10.1002/jts.2490020207

Shapiro, F. (2001). Eye Movement Desensitization and Reprocessing. Basic Principles, Protocols, and Procedures. New York: The Guilford Press.

\section{Copyrights}

Copyright for this article is retained by the author(s), with first publication rights granted to the journal.

This is an open-access article distributed under the terms and conditions of the Creative Commons Attribution license (http://creativecommons.org/licenses/by/4.0/). 